\title{
Artificial Neural Network Modeling of Drying Kinetics and Color Changes of Ginkgo Biloba Seeds during Microwave Drying Process
}

\author{
Jun-Wen Bai $\mathbb{D},{ }^{1}$ Hong-Wei Xiao $\mathbb{D}^{2},{ }^{2}$ Hai-Le Ma $\mathbb{D}^{1},{ }^{1}$ and Cun-Shan Zhou $\mathbb{D}^{1}$ \\ ${ }^{1}$ School of Food and Biological Engineering, Jiangsu University, Zhenjiang 212013, China \\ ${ }^{2}$ College of Engineering, China Agricultural University, Beijing 100083, China \\ Correspondence should be addressed to Cun-Shan Zhou; cunshanzhou@163.com
}

Received 21 September 2017; Revised 16 January 2018; Accepted 28 January 2018; Published 21 February 2018

Academic Editor: Egidio De Benedetto

Copyright (C) 2018 Jun-Wen Bai et al. This is an open access article distributed under the Creative Commons Attribution License, which permits unrestricted use, distribution, and reproduction in any medium, provided the original work is properly cited.

Ginkgo biloba seeds were dried in microwave drier under different microwave powers $(200,280,460$, and $640 \mathrm{~W})$ to determinate the drying kinetics and color changes during drying process. Drying curves of all samples showed a long constant rate period and falling rate period along with a short heating period. The effective moisture diffusivities were found to be $3.318 \times 10^{-9}$ to $1.073 \times$ $10^{-8} \mathrm{~m}^{2} / \mathrm{s}$ within the range of microwave output levels and activation energy was $4.111 \mathrm{~W} / \mathrm{g}$. The $L^{*}$ and $b^{*}$ values of seeds decreased with drying time. However, $a^{*}$ value decreased firstly and then increased with the increase of drying time. Artificial neural network (ANN) modeling was employed to predict the moisture ratio and color parameters $\left(L^{*}, a^{*}\right.$, and $\left.b^{*}\right)$. The ANN model was trained for finite iteration calculation with Levenberg-Marquardt algorithm as the training function and tansig-purelin as the network transfer function. Results showed that the ANN methodology could precisely predict experimental data with high correlation coefficient (0.9056-0.9834) and low mean square error (0.0014-2.2044). In addition, the established ANN models can be used for online prediction of moisture content and color changes of ginkgo biloba seeds during microwave drying process.

\section{Introduction}

Ginkgo biloba (GB) is the oldest relict plant of the extant gymnosperms and is referred to as an archaic living fossil. GB is native to China, and the cultivation area in China accounts for $90 \%$ of the worldwide cultivated land of GB trees [1]. In some oriental countries, including China, Japan, and Korea, GB seeds are regarded as delicious food and tonic medicine, which is a rich source of health-promoting compounds such as flavonoids, ginkgo acid, bilobol, and ginkgolides as well as carbohydrates, protein, fats, vitamins, and mineral elements [2]. As a seasonal nut, in China, GB is generally harvested in late September to October, which is a typical seasonal crop. Although it is wrapped by a hard shell, GB seed cannot be stored for a long time due to its relative high moisture content. Drying is one of the most frequently used methods to prolong the shelf life of GB seeds. The dried products can be used as materials for further processing for other products such as GB seeds powers.
The traditional drying methods for GB seeds are natural sun drying and hot air drying. Although both methods are relatively simple and inexpensive, they have several disadvantages such as long drying time, low energy efficiency, and substantial deterioration of food quality, such as degradation of color and loss of nutrients. Microwave drying is a technique that can be used as an alternative to shorten the drying time, improve the quality of the dried products, and reduce energy consumption [3]. Microwaves can penetrate into the material with the effect known as volumetric hearting [4], which can increase the drying rate in the falling drying rate period [5]. Microwave drying technology has been applied to several fruits and vegetables, such as carrot [6], nut seed [7], blueberry [8], apple slices [9], thyme leaves [10], and jujube [11].

Drying is a complex, dynamic, highly nonlinear, strongly interactive, and multivariable thermal process [12]. Therefore, the prediction of moisture content and quality parameters are very useful and necessary to improve the overall performance of drying process. Researchers usually develop mathematical 
models which can be classified as theoretical, semitheoretical, and empirical models to describe the drying kinetics and quality changes. Although these models can give good regression to experimental data in very specific conditions, there is no way to obtain general equations to describe the drying process of every product [13].

Artificial neural networks (ANN) offer several advantages over conventional modeling techniques because of the learning ability and being suitable to the nonlinear process. ANN models have been developed to model the moisture content and quality parameters in drying process. Jafari et al. [14] observed that ANN model was more productive and precise than mathematical modeling method for predicting changes in the moisture ratio of green bell pepper during hot air fluidized bed drying. Sarimeseli et al. [10] used ANN to describe microwave drying kinetics of thyme leaves. Behroozi Khazaei et al. [15] applied machine vision and ANN for modeling and controlling of the grape drying process in hot air dryer. Nadian et al. [16] developed an ANN model to predict the color changes of apple slices during hot air drying. Guiné et al. [17] employed ANN to characterize the antioxidant activity and phenolic compounds degradation kinetics of bananas under different drying conditions.

The objectives of current work are (i) to explore the drying characteristic and color changes kinetic of GB seeds at different microwave powers, (ii) to calculate effective moisture diffusivity and the activation energy to highlight the effect of microwave power, and (iii) to model the experimental drying kinetics and color changes of GB seeds during its microwave drying process using ANN methodology.

\section{Materials and Methods}

2.1. Materials. Fresh GB seeds were purchased from a local market in Taixing, China. The cultivar of GB is Dafozi. To ensure uniformity of physical characteristics of the experimental materials, the samples were carefully selected with the same size (average major axis, middle axle, and minor axis were $22.07 \mathrm{~mm}, 13.84 \mathrm{~mm}$, and $12.03 \mathrm{~mm}$, resp.). The initial moisture content of samples was determined by vacuum drying at $70^{\circ} \mathrm{C}$ for $24 \mathrm{~h}$ following the standard method (AOAC, 1990). The initial moisture content of the samples was reported as $53.02 \%$ in wet basis (w.b.) or $1.13 \mathrm{~kg} / \mathrm{kg}$ in dry basis (d.b.). Prior to experiments, the kernel (nut meat) of the GB seed was obtained by shelling and removing the bronzing pellicle. All the GB seeds were stored in a refrigerator at $5 \pm 1^{\circ} \mathrm{C}$ and $90 \%$ relative humidity before the experiments were carried out.

2.2. Drying Experiments. Drying experiments were carried out in a domestic digital microwave oven with maximum power output capacity of $700 \mathrm{~W}$ at $2450 \mathrm{MHz}$ (P70d2otl, Galanz, China). The microwave oven has a capability to operate at four different microwave output powers (200, 280,460 , and $640 \mathrm{~W}$ ), with measurement accuracy of $\pm 10 \mathrm{~W}$. Processing time and microwave output power were adjusted with the digital control on the microwave oven. GB seeds of $80 \mathrm{~g}$ were placed in a single layer on a rotating glass plate in the oven. The weight loss was periodically recorded by taking out the rotating glass and weighing it on an electronic balance within the accuracy of $\pm 0.01 \mathrm{~g}$ during drying. Drying was stopped when the moisture content of the samples reached the final moisture content of $0.15 \mathrm{~kg} / \mathrm{kg}$ (d.b.). All the drying experiments were conducted in triplicate.

2.3. Calculation of Moisture Ratio and Drying Rate. The moisture ratio (MR) of the samples was calculated according to [23]

$$
\mathrm{MR}=\frac{M_{t}-M_{e}}{M_{0}-M_{e}},
$$

where $M_{t}, M_{0}$, and $M_{e}$ are moisture content at any time of drying (kg water/kg dry matter), initial moisture content (kg water/kg dry matter), and equilibrium moisture content ( $\mathrm{kg}$ water/kg dry matter), respectively. The equilibrium moisture content was assumed to be zero for microwave drying as stated by Maskan [24].

The drying rate (DR) of samples during drying experiments was computed using [18]

$$
\mathrm{DR}=\frac{M_{t+d t}-M_{t}}{d t}
$$

where $M_{t}$ and $M_{t+d t}$ are the moisture content at $t$ and moisture content at $t+d t$ ( $\mathrm{kg}$ water $/ \mathrm{kg}$ dry matter), respectively, and $t$ is drying time ( $\mathrm{min})$.

2.4. Calculation of Effective Moisture Diffusivity. Weibull distribution can be used to calculate the effective moisture diffusivity, regardless of the characteristics of moisture migration during drying process. The MR curves were fitted to the Weibull distribution [25]

$$
\mathrm{MR}=\exp \left[-\left(\frac{t}{\alpha}\right)^{\beta}\right]
$$

where MR is moisture ratio of GB seeds; $t$ is the drying time; $\alpha$ is the scale parameter of Weibull distribution ( $\mathrm{min}) ; \beta$ is the shape parameter of Weibull distribution.

Effective moisture diffusivity $\left(D_{\text {eff }}\right)$ can be calculated with the following equation $[25,26]$ :

$$
D_{\mathrm{eff}}=\frac{D_{\mathrm{cal}}}{R_{g}}=\frac{r^{2}}{\alpha R_{g}},
$$

where $D_{\text {eff }}$ is the effective moisture diffusivity $\left(\mathrm{m}^{2} / \mathrm{s}\right) ; D_{\text {cal }}$ is the estimate moisture diffusivity $\left(\mathrm{m}^{2} / \mathrm{s}\right) ; r$ is the volume equivalent radius of GB seeds, with $0.769 \times 10^{-2} \mathrm{~m}$ as its value; $\alpha$ is the scale parameter of Weibull distribution; $R_{g}$ is the physical dimension constant. For agriculture products with a shape of sphere, the value of $R_{g}$ is 18.6 [27].

2.5. Estimation of Activation Energy. Activation energy $\left(E_{a}\right)$ is the minimum energy that must be supplied to break watersolid and/or water-water interactions and to move water molecules from one point to another in solid [3]. The dependence of effective moisture diffusivity on drying temperature 


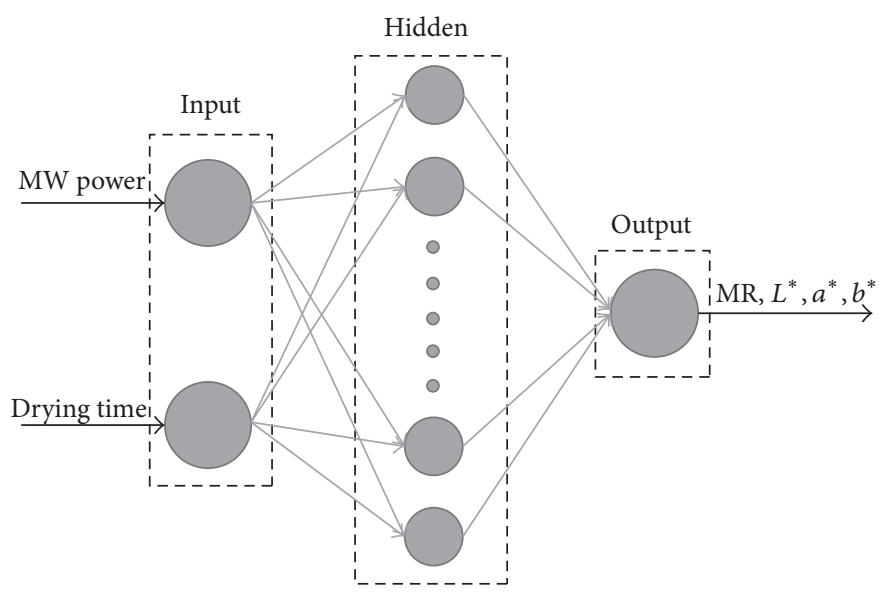

FIgURE 1: Artificial neural network configuration.

has been shown to follow an Arrhenius relationship presented as follows:

$$
D_{\text {eff }}=D_{0} \exp \left(-\frac{E_{a}}{R(T+273.15)}\right),
$$

where $D_{0}$ is the preexponential factor of Arrhenius equation $\left(\mathrm{m}^{2} / \mathrm{s}\right) ; E_{a}$ is the activation energy $(\mathrm{kJ} / \mathrm{mol}) ; R$ is the universal gas constant $(\mathrm{kJ} / \mathrm{mol} \mathrm{K}) ; T$ is temperature $\left({ }^{\circ} \mathrm{C}\right)$.

However, during the microwave drying processes, the temperature is not a directly measured variable. The Arrhenius equation was used in a modified form to illustrate the relationship between the effective moisture diffusion and the ratio of the microwave output power to sample weight $(\mathrm{m} / \mathrm{P})$ instead of the temperature for calculation of the activation energy. The modified Arrhenius equation (6) derived by Dadalı et al. [18] can be effectively used as follows:

$$
D_{\text {eff }}=D_{0} \exp \left(-\frac{E_{a} m}{P}\right)
$$

where $D_{0}$ is the preexponential factor of Arrhenius equation $\left(\mathrm{m}^{2} / \mathrm{s}\right) ; D_{\text {eff }}$ is the effective moisture diffusivity $\left(\mathrm{m}^{2} / \mathrm{s}\right) ; E_{a}$ is the activation energy $(\mathrm{W} / \mathrm{g}) ; m$ is the mass of raw sample $(\mathrm{g})$; $P$ is the microwave power $(\mathrm{W})$.

Equation (6) can be expressed in a logarithmic form as follows:

$$
\ln D_{\text {eff }}=\ln D_{0}-\frac{E_{a} m}{P} .
$$

So the activation energy can be calculated from the slope of $\ln \left(D_{\text {eff }}\right)$ versus the ratio of the microwave output power to sample weight $(m / P)$.

2.6. Color Measurement. A CIE standard illuminant D65 and observer $10^{\circ}$ were used to determine CIE color space coordinates, $L^{*}$ (whiteness or brightness), $a^{*}$ (redness/greenness), and $b^{*}$ (yellowness/blueness). GB seed samples color was measured using a colorimeter (Color Quest X, Hunter Lab, USA) before drying and prespecified time intervals during drying. Three samples were randomly selected for color measurement. $L^{*}, a^{*}$, and $b^{*}$ values of each sample were average of 6 readings.
2.7. ANN Modeling. MATLAB software (Version 7.8, MathWorks, USA) was used for the design and testing of various ANN models. The ANN configuration used in this work (Figure 1) was a multilayer "feed-forward," consisting of one input layer, one hidden layer, and one output layer with a convergence criterion for training purposes. The input variables in the input layer are microwave power and drying time and the output variables in the output layer are moisture content and the color parameters $\left(L^{*}, a^{*}\right.$, and $\left.b^{*}\right)$ of GB seeds at any time. After trial and error, network unit with hyperbolic tangent sigmoid transfer function "tansig" for neurons of hidden layer, 10 neurons in the hidden layer, linear transfer function "purelin" for neuron of output layer, and Levenberg-Marquardt training algorithm "trainlm" for the training function were selected.

In this study, input-output data sets collected in the experiment were totally 120 and 114 for $\mathrm{MR}$ and color parameters $\left(L^{*}, a^{*}\right.$, and $\left.b^{*}\right)$, respectively. For ANN model building, the available data were randomly divided into 3 subsets: training (70\%), validation (15\%), and testing (15\%) subset. The networks performance was evaluated by correlation coefficient $\left(R^{2}\right)$ and mean square error (RMSE). These statistical values can be calculated as follows:

$$
\begin{aligned}
R^{2} & =1-\frac{\sum_{i=1}^{N}\left(C_{\text {pre }, i}-C_{\text {exp }, i}\right)^{2}}{\sum_{i=1}^{N}\left(\overline{C_{\text {pre }}}-C_{\text {exp }, i}\right)^{2}}, \\
\text { RMSE } & =\left[\frac{1}{N} \sum_{i=1}^{N}\left(C_{\text {pre }, i}-C_{\text {exp }, i}\right)^{2}\right]^{1 / 2},
\end{aligned}
$$

where $C_{\text {exp }, i}$ is the $i$ th experimental data, $C_{\mathrm{pre}, i}$ is the $i$ th predicted data by ANN model, and $N$ is the number of experimental data.

\section{Result and Discussion}

3.1. Drying Curves. To investigate the effects of microwave power on moisture ratio and drying time, the curves of MR versus drying time are shown in Figure 2. From Figure 2, 
TABLE 1: Moisture effective diffusion coefficients of GB seeds by different microwave powers.

\begin{tabular}{lcccc}
\hline Powers $(\mathrm{W})$ & $\alpha(\mathrm{min})$ & $\beta$ & $R^{2}$ & $D_{\text {eff }}\left(10^{-9} \mathrm{~m}^{2} / \mathrm{s}\right)$ \\
\hline 200 & 15.97 & 1.909 & 0.9999 & 3.318 \\
280 & 9.337 & 1.850 & 0.9999 & 5.675 \\
460 & 6.530 & 1.884 & 1.0000 & 8.114 \\
640 & 4.941 & 2.038 & 0.9999 & 10.73 \\
\hline
\end{tabular}

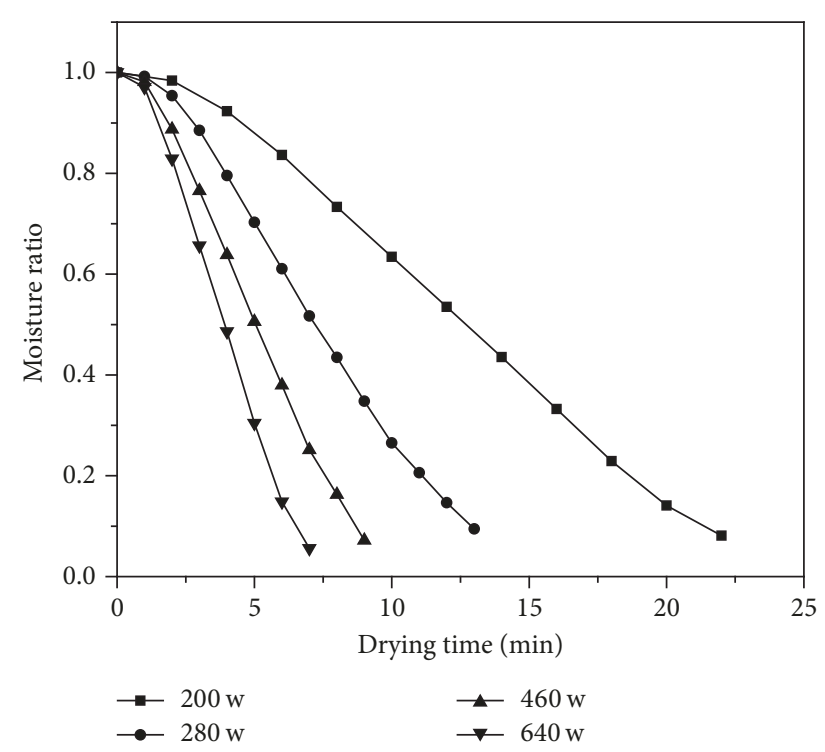

FIGURE 2: Drying kinetics of GB seeds under different microwave powers.

it was shown that drying time required to reduce the moisture from the initial moisture content to desired moisture content for GB seeds was approximately 22, 13, 9, and $7 \mathrm{~min}$, respectively, in relation to the microwave power of 200, 280, 460 , and $640 \mathrm{~W}$. The drying time was approximately 3.14 times more at $200 \mathrm{~W}$ than that at $640 \mathrm{~W}$. Therefore, it can be concluded that microwave power had significant effect on the drying time. The results indicated that mass transfer is rapid during the higher microwave power heating as a result of more energy transfer to the samples, causing an increase in temperature of the product $[28,29]$. This phenomenon was in agreement with reported literatures for drying parsley [30], sardine fish [19], and tea [31].

The drying rate curves for GB seeds under different microwave powers were given in Figure 3. As can be seen from this figure, the drying rate of samples was apparently increased as the microwave power level was increased. After a short preheating period, a long constant drying rate period was observed in all cases and the average drying rates at constant rate period ranged from about 0.04 to 0.16 (g water/g solid $\mathrm{min}$ ) for the microwave power between 200 and $640 \mathrm{w}$, respectively. As the drying processed, when the material moisture content was lower than about 0.42 (g water/g solid $\mathrm{min}$ ), a constant rate period was followed by a falling rate period which was controlled by the internal liquid diffusion. The loss of moisture content of samples caused a decrease in the absorption of microwave power and led to a descending

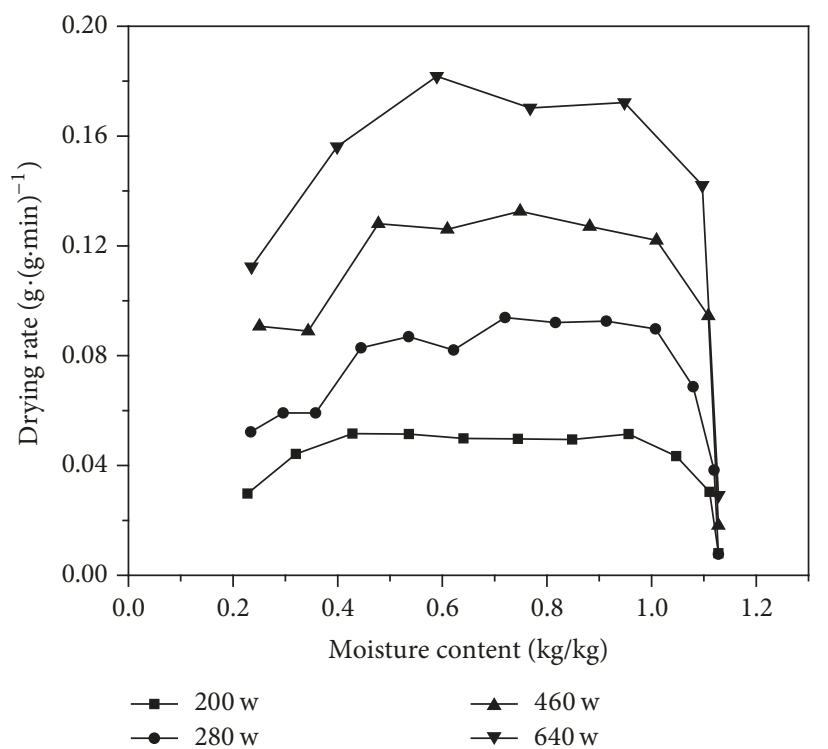

FIGURE 3: Drying rate of GB seeds under different microwave powers.

in the drying rate $[32,33]$. These results were in agreement with the study of microwave drying of okra [34], coriander leaves [35], onion slices [20], and daylily flower buds [33], which indicated that a long constant rate period and falling rate period were observed after a short heating period. On the other hand, these results were not the same as the studies performed by Ozkan et al. [32] and Balbay and Şahin [36], both of the investigations claimed that microwave drying of liquorice root or spinach occurred only in the falling rate period. The reason for differences may be ascribed to the different structures and sizes of materials.

3.2. Effective Moisture Diffusivity and Activation Energy. The effective moisture diffusivity values of GB seeds were calculated using Weibull distribution and (4) and are shown in Table 1 . The $D_{\text {eff }}$ values of dried samples were varied in the range of $3.318 \times 10^{-9}$ to $1.073 \times 10^{-8} \mathrm{~m}^{2} / \mathrm{s}$ under different microwave powers. The values of the Weibull scale parameter $(\alpha)$ ranged from 4.941 to $15.97 \mathrm{~min}$ and values of the shape parameter $(\beta)$ varied from 1.8502 to 2.0378 . It was noted that $D_{\text {eff }}$ values increased greatly with increasing microwave powers. When samples were dried at higher microwave power, increased heating energy would increase the activity of water molecules leading to higher moisture diffusivity [37]. The values of $D_{\text {eff }}$ obtained from this study lie within the general range from $10^{-12}$ to $10^{-8} \mathrm{~m}^{2} / \mathrm{s}$ for food materials [37]. 


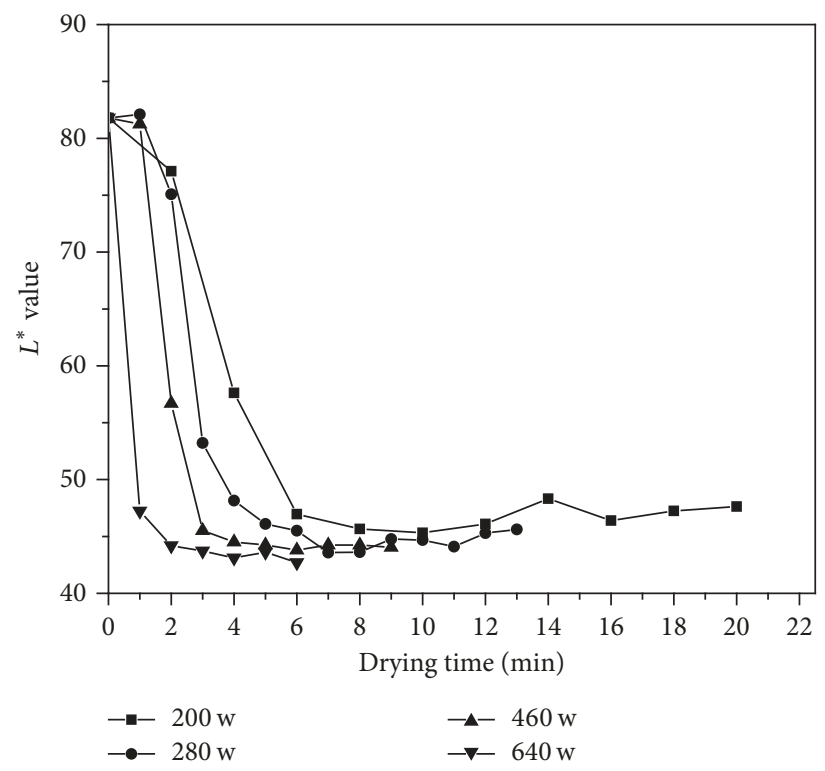

(a)

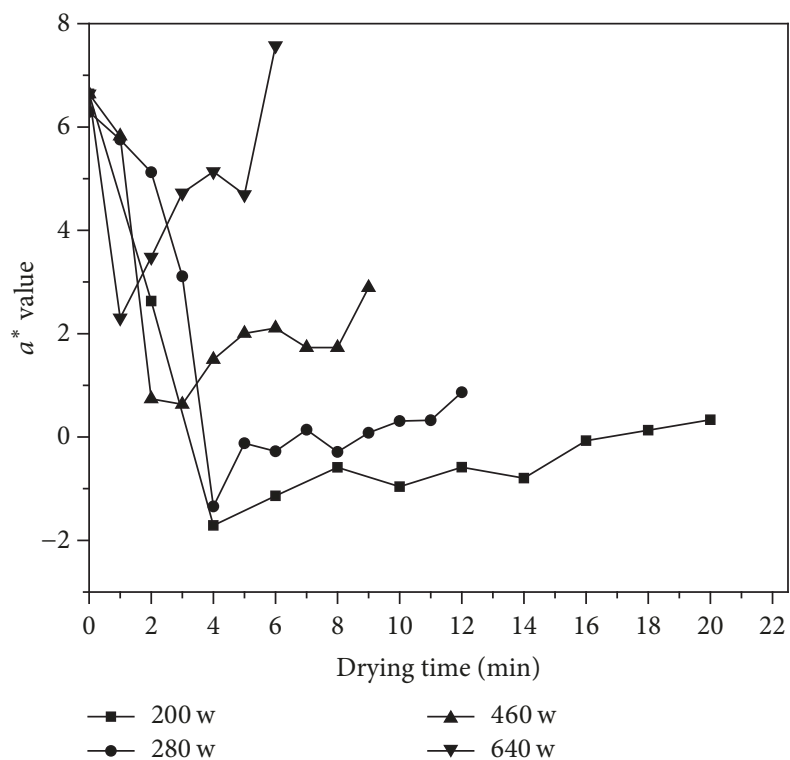

(b)

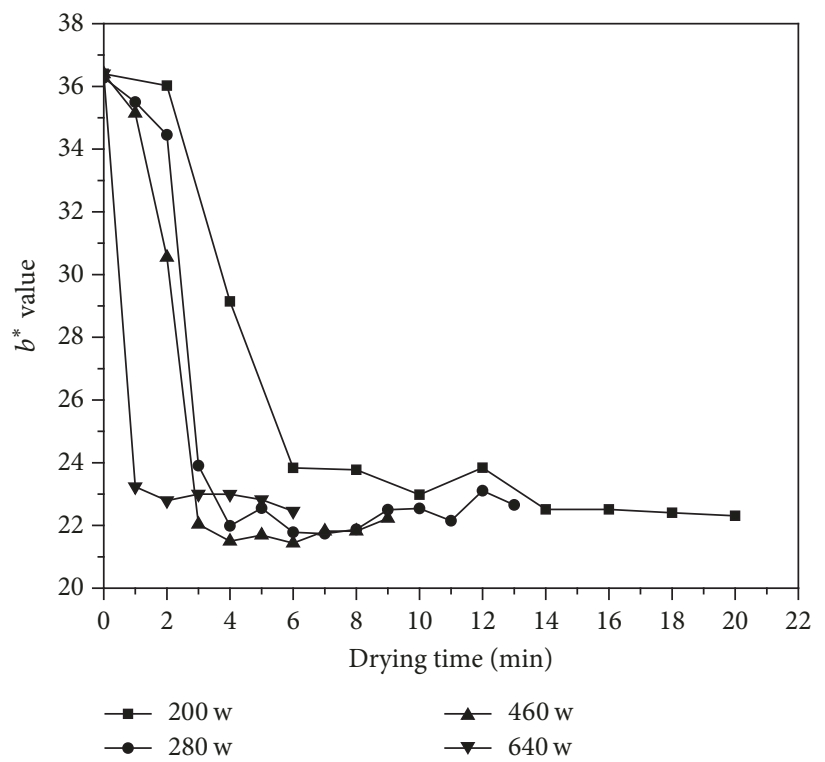

(c)

Figure 4: Color changes of (a) $L^{*}$ value, (b) $a^{*}$ value, and (c) $b^{*}$ value as a function of drying time at various microwave powers for sample amount of $80 \mathrm{~g}$.

The activation energy is the energy required to initiate moisture diffusion from inside to the outside of the drying product. The $E_{a}$ value for GB seeds was determined to be $4.111 \mathrm{~W} / \mathrm{g}$, which can be calculated from the slope of $\ln \left(D_{\text {eff }}\right)$ versus the ratio of the microwave power to sample weight $(m / P)$. To compare the activation energy of GB seeds with other agricultural products, the activation energy of various agricultural materials is presented in Table 2. Table 2 shows that GB seeds have lower activation energy than that for sardine fish, mint leaves, okra, and onion slices. And the value of $E_{a}$ found from this study was quite similar to the value of apple slices $(4.140 \mathrm{~W} / \mathrm{g})$. A lower $E_{a}$ value indicates greater temperature sensitivity of diffusion coefficient and less energy required to remove moisture from the product [3]. In general, the factors such as the components, variety, and tissue structures of the samples have a significant effect on activation energy.

3.3. Color Change Kinetics during Drying Process. The color change curves of $L^{*}, a^{*}$, and $b^{*}$ value as a function of drying time under various microwave powers were shown in Figures 4(a) $-4(\mathrm{c})$. The $L^{*}$ value is illustrated in Figure 4(a). As can be seen from this figure, $L^{*}$ value decreased with drying time and all dried GB seeds were obviously darker than the fresh samples. It has been stated that the decrease of the brightness of dried samples can be taken as an indicator of browning 


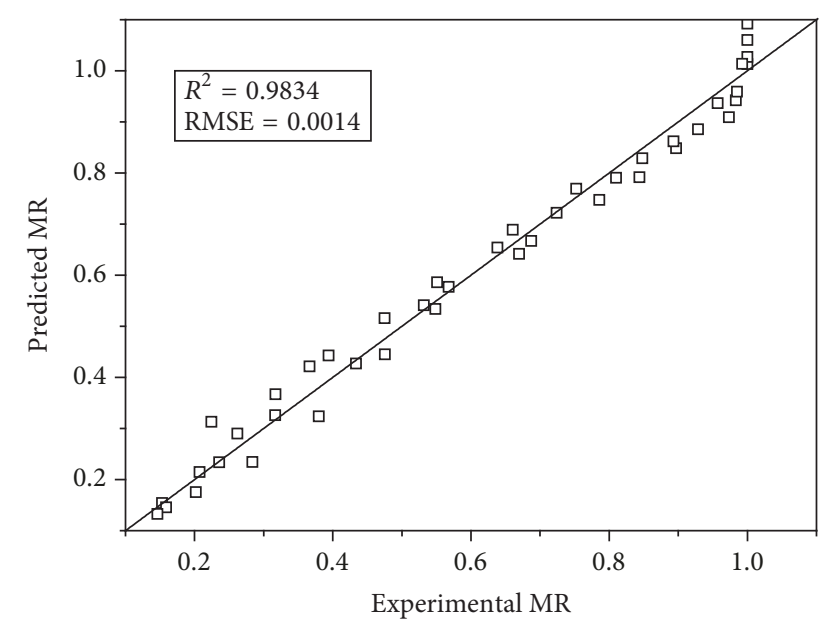

(a)

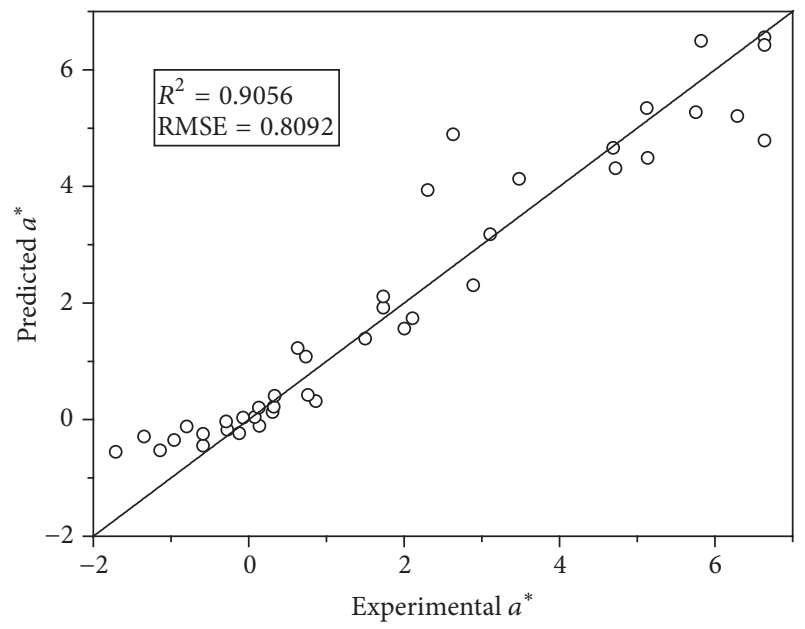

(c)

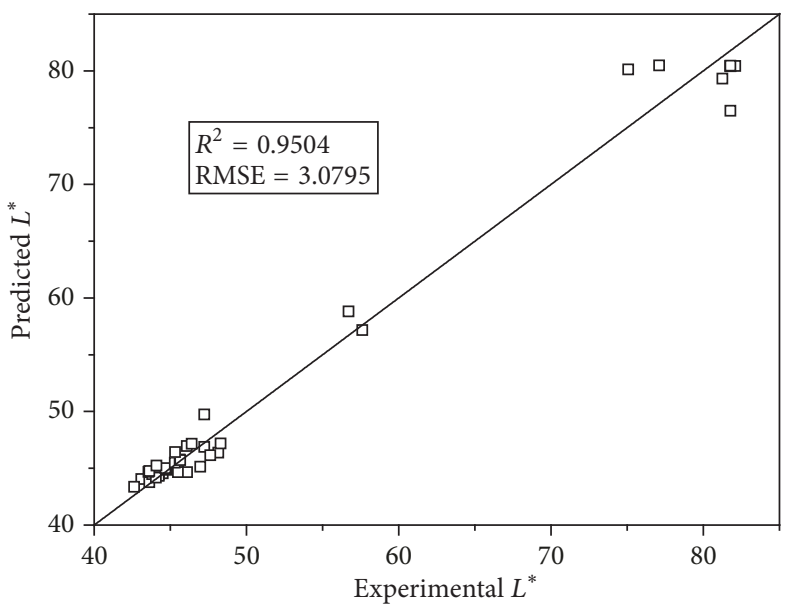

(b)

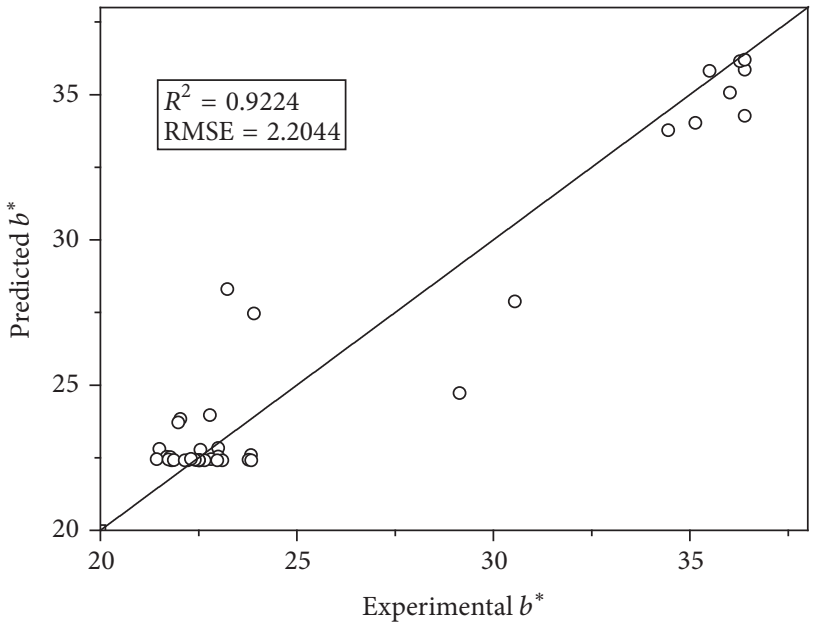

(d)

FIGURE 5: Comparison of predicted and experimental moisture ratio and color parameters $\left(L^{*}, a^{*}\right.$, and $\left.b^{*}\right)$ on testing step for the optimal ANN topology.

[38]. Besides, the $L^{*}$ values of final dried samples were about $47.62,45.62,44.05$, and 42.63 under the microwave power of 200, 280, 460, and $640 \mathrm{~W}$, respectively. The differences might be due to the Maillard reaction, which was accelerated at higher temperature. Similar phenomenon was in agreement with the study for drying spinach published by Dadalı et al. [39] and for drying tea published by Demirhan and Ozbek [40].

The results for $a^{*}$ value are shown in Figure 4(b). It was found that $a^{*}$ value of GB seeds decreased firstly and then increased with the increase of drying time in all cases. The lowest $a^{*}$ of samples were about $-1.71,-1.34,0.63$, and 2.31 under the microwave power of $200,280,460$, and $640 \mathrm{~W}$, respectively. The negative $a^{*}$ value appeared when drying for $4 \mathrm{~min}$ under the microwave power of 200 and $280 \mathrm{w}$, indicating that the samples turned to be greenish. It may be due to that the surface of GB seeds became transparent and showed the color of internal germ. After $a^{*}$ value reached its lowest point, it had begun to increase with the drying time, which indicated that the color of the samples became more reddish. Figure 4(b) also showed that, at the end of drying, $a^{*}$ value increased as the microwave power increased. The final $a^{*}$ values of dried samples were about $0.34,2.58,2.89$, and 7.57 under the microwave power of $200,280,460$, and $640 \mathrm{~W}$, respectively. This phenomenon could be attributed to the creation of red-brown pigments in the effect of nonenzymatic reaction $[41,42]$.

The results for $b^{*}$ values are shown in Figure 4(c). As can be seen from this figure, $b^{*}$ values decreased with drying time and indicate that the yellowness of sample decreased due to microwave power applied. In addition, the change rate of $b^{*}$ value was faster at the initial drying stage than that at the intermediate and final drying stages.

3.4. ANN Modeling. The BP neural network model was trained for finite iteration calculation with LevenbergMarquardt algorithm as the training function and tansigpurelin as the network transfer function. The experimental and predicted moisture ratio and color parameters $\left(L^{*}, a^{*}\right.$, and $b^{*}$ ) values for the optimal ANN topology were shown in Figure 5. The determination coefficient $\left(R^{2}\right)$ and root mean squared error (RMSE) between the predicted and 
TABLE 2: Activation energies of GB seeds and other products under microwave drying.

\begin{tabular}{lccc}
\hline Products & $\begin{array}{c}\text { Microwave } \\
\text { power }(\mathrm{W})\end{array}$ & $\begin{array}{c}\text { Activation } \\
\text { energy }(\mathrm{W} / \mathrm{g})\end{array}$ & References \\
\hline GB seeds & $200-640$ & 4.111 & Present work \\
Okra & $180-900$ & 5.540 & {$[18]$} \\
Sardine fish & $200-500$ & 11.14 & {$[19]$} \\
Onion slices & $328-557$ & 7.900 & {$[20]$} \\
Mint leaves & $180-900$ & 11.04 & {$[21]$} \\
Apple slices & $200-600$ & 4.140 & {$[22]$} \\
\hline
\end{tabular}

measured values were 0.9834 and 0.0014 for moisture content, 0.9504 and 3.0795 for $L^{*}$ value, 0.9056 and 0.8092 for $a^{*}$ value, and 0.9224 and 2.2044 for $b^{*}$ value, respectively. An acceptable level of statistical parameters of $R^{2}$ and RMSE was obtained by employing the selected ANN. The best and worst estimations were obtained for the moisture ratio and $a^{*}$ value. In general, there was a good agreement between experimental and estimated values, demonstrating that the selected ANN topology had an acceptable capability to predict the network outputs with the inconsiderable error. Therefore, according to the results of this experimental study as well as ANN modeling, the online prediction moisture content and color evaluation would be proposed as a promising methodology for GB seeds drying process.

\section{Conclusions}

Ginkgo biloba seeds were dried in microwave drier to determinate the drying kinetics and color changes during drying process. Microwave power had significant effect on the drying time, and higher microwave power results in higher drying rate and shorter drying time. Within the range of microwave output levers $(200,280,460$, and $640 \mathrm{w})$, effective moisture diffusivities were found to be $3.318 \times 10^{-9}$ to $1.073 \times$ $10^{-8} \mathrm{~m}^{2} / \mathrm{s}$ and activation energy was estimated to be $4.111 \mathrm{~W} / \mathrm{g}$. The $L^{*}$ and $b^{*}$ values of GB seeds decreased with drying time. However, $a^{*}$ value decreased firstly and then increased with the increase of drying time. ANN modeling was applied to predict the moisture ratio and color parameters $\left(L^{*}, a^{*}\right.$, and $b^{*}$ ). The results showed that the ANN methodology could precisely model the microwave drying process of GB seeds with correlation coefficient higher than 0.9056. The findings in current work demonstrated that the selected ANN topology had an acceptable capability to predict the network outputs with the inconsiderable error.

\section{Conflicts of Interest}

The authors declare that they have no conflicts of interest.

\section{Acknowledgments}

The authors acknowledge the financial support provided by the National Natural Science Foundation of China (31601578), the National Key Research and Development Plan
(2017YFD0400905), and the Natural Science Foundation of Jiangsu Province (BK20160504).

\section{References}

[1] M. Miao, H. Jiang, B. Jiang, S. W. Cui, Z. Jin, and T. Zhang, "Structure and functional properties of starches from Chinese ginkgo (Ginkgo biloba L.) nuts," Food Research International, vol. 49, no. 1, pp. 303-310, 2012.

[2] C. H. Zhang, L. X. Huang, C. P. Wang, and A. S. Mujumdar, "Experimental and numerical investigation of spray-drying parameters on the dried powder properties of ginkgo biloba seeds," Drying Technology, vol. 28, no. 3, pp. 380-388, 2010.

[3] V. Kumar, H. K. Sharma, and K. Singh, "Mathematical Modeling of Thin Layer Microwave Drying of Taro Slices," Journal of The Institution of Engineers (India): Series A, vol. 97, no. 1, pp. 53-61, 2016.

[4] D. Wray and H. S. Ramaswamy, "Novel Concepts in Microwave Drying of Foods," Drying Technology, vol. 33, no. 7, pp. 769-783, 2015.

[5] G. R. Nair, Z. Li, Y. Gariepy, and V. Raghavan, "Microwave drying of corn (Zea mays L. ssp.) for the seed industry," Drying Technology, vol. 29, no. 11, pp. 1291-1296, 2011.

[6] H. Pu, Z. Li, J. Hui, and G. S. V. Raghavan, "Effect of relative humidity on microwave drying of carrot," Journal of Food Engineering, vol. 190, pp. 167-175, 2016.

[7] A. C. da Silva, H. J. Sarturi, E. L. Dall'Oglio et al., "Microwave drying and disinfestation of Brazil nut seeds," Food Control, vol. 70, pp. 119-129, 2016.

[8] M. Zielinska and M. Markowski, "The influence of microwaveassisted drying techniques on the rehydration behavior of blueberries (Vaccinium corymbosum L.)," Food Chemistry, vol. 196, pp. 1188-1196, 2016.

[9] M. Zarein, S. H. Samadi, and B. Ghobadian, "Investigation of microwave dryer effect on energy efficiency during drying of apple slices," Journal of the Saudi Society of Agricultural Sciences, vol. 14, no. 1, pp. 41-47, 2015.

[10] A. Sarimeseli, M. A. Coskun, and M. Yuceer, "Modeling Microwave Drying Kinetics of Thyme (Thymus Vulgaris L.) Leaves Using ANN Methodology and Dried Product Quality," Journal of Food Processing and Preservation, vol. 38, no. 1, pp. 558-564, 2014.

[11] S. Fang, Z. Wang, X. Hu et al., "Energy requirement and quality aspects of Chinese jujube (Zizyphus jujuba Miller) in hot air drying followed by microwave drying," Journal of Food Process Engineering, vol. 34, no. 2, pp. 491-510, 2011.

[12] M. Aghbashlo, S. Hosseinpour, and A. S. Mujumdar, "Application of Artificial Neural Networks (ANNs) in Drying Technology: A Comprehensive Review," Drying Technology, vol. 33, no. 12, pp. 1397-1462, 2015.

[13] V. Martínez-Martínez, J. Gomez-Gil, T. S. Stombaugh, M. D. Montross, and J. M. Aguiar, "Moisture Content Prediction in the Switchgrass (Panicum virgatum) Drying Process Using Artificial Neural Networks," Drying Technology, vol. 33, no. 14, pp. 1708-1719, 2015.

[14] S. M. Jafari, V. Ghanbari, M. Ganje, and D. Dehnad, "Modeling the Drying Kinetics of Green Bell Pepper in a Heat Pump Assisted Fluidized Bed Dryer," Journal of Food Quality, vol. 39, no. 2, pp. 98-108, 2016.

[15] N. Behroozi Khazaei, T. Tavakoli, H. Ghassemian, M. H. Khoshtaghaza, and A. Banakar, "Applied machine vision and 
artificial neural network for modeling and controlling of the grape drying process," Computers and Electronics in Agriculture, vol. 98, pp. 205-213, 2013.

[16] M. H. Nadian, S. Rafiee, M. Aghbashlo, S. Hosseinpour, and S. S. Mohtasebi, "Continuous real-time monitoring and neural network modeling of apple slices color changes during hot air drying," Food and Bioproducts Processing, vol. 94, pp. 263-274, 2015.

[17] R. P. F. Guiné, M. J. Barroca, F. J. Gonçalves, M. Alves, S. Oliveira, and M. Mendes, "Artificial neural network modelling of the antioxidant activity and phenolic compounds of bananas submitted to different drying treatments," Food Chemistry, vol. 168, pp. 454-459, 2015.

[18] G. Dadalı, D. K. Apar, and B. Özbek, "Microwave drying kinetics of okra," Drying Technology, vol. 25, no. 5, pp. 917-924, 2007.

[19] H. Darvishi, M. Azadbakht, A. Rezaeiasl, and A. Farhang, "Drying characteristics of sardine fish dried with microwave heating," Journal of the Saudi Society of Agricultural Sciences, vol. 12, no. 2, pp. 121-127, 2013.

[20] E. Demiray, A. Seker, and Y. Tulek, "Drying kinetics of onion (Allium cepa L.) slices with convective and microwave drying," Heat and Mass Transfer, vol. 53, no. 5, pp. 1817-1827, 2017.

[21] B. Özbek and G. Dadali, "Thin-layer drying characteristics and modelling of mint leaves undergoing microwave treatment," Journal of Food Engineering, vol. 83, no. 4, pp. 541-549, 2007.

[22] N. Aghilinategh, S. Rafiee, A. Gholikhani et al., "A comparative study of dried apple using hot air, intermittent and continuous microwave: Evaluation of kinetic parameters and physicochemical quality attributes," Food Science \& Nutrition, vol. 3, no. 6, pp. 519-526, 2015.

[23] E. E. Abano, H. Ma, and W. Qu, "Influence of combined microwave-vacuum drying on drying kinetics and quality of dried tomato slices," Journal of Food Quality, vol. 35, no. 3, pp. 159-168, 2012.

[24] M. Maskan, "Microwave/air and microwave finish drying of banana," Journal of Food Engineering, vol. 44, no. 2, pp. 71-78, 2000.

[25] L. Xie, A. S. Mujumdar, X.-M. Fang et al., "Far-infrared radiation heating assisted pulsed vacuum drying (FIR-PVD) of wolfberry (Lycium barbarum L.): Effects on drying kinetics and quality attributes," Food and Bioproducts Processing, vol. 102, pp. 320-331, 2017.

[26] J.-W. Dai, J.-Q. Rao, D. Wang et al., "Process-Based Drying Temperature and Humidity Integration Control Enhances Drying Kinetics of Apricot Halves," Drying Technology, vol. 33, no. 3, pp. 365-376, 2015.

[27] A. Marabi, S. Livings, M. Jacobson, and I. S. Saguy, "Normalized Weibull distribution for modeling rehydration of food particulates," European Food Research and Technology, vol. 217, no. 4, pp. 311-318, 2003.

[28] L. M. Bal, A. Kar, S. Satya, and S. N. Naik, "Drying kinetics and effective moisture diffusivity of bamboo shoot slices undergoing microwave drying," International Journal of Food Science \& Technology, vol. 45, no. 11, pp. 2321-2328, 2010.

[29] A. S. Kipcak, "Microwave drying kinetics of mussels (Mytilus edulis)," Research on Chemical Intermediates, vol. 43, no. 3, pp. 1429-1445, 2017.

[30] Y. Soysal, "Microwave drying characteristics of parsley," Biosystems Engineering, vol. 89, no. 2, pp. 167-173, 2004.
[31] D. Hatibaruah, D. C. Baruah, and S. Sanyal, "Microwave drying characteristics of assam ctc tea (camellia assamica)," Journal of Food Processing and Preservation, vol. 37, no. 4, pp. 366-370, 2013.

[32] I. A. Ozkan, B. Akbudak, and N. Akbudak, "Microwave drying characteristics of spinach," Journal of Food Engineering, vol. 78, no. 2, pp. 577-583, 2007.

[33] S. Ding, J. You, K. An, Y. Li, and Z. Wang, "Effective diffusivities and energy consumption of daylily in microwave drying," International Journal of Food Science \& Technology, vol. 47, no. 12, pp. 2648-2654, 2012.

[34] G. Dadal, D. K. Apar, and B. Özbek, "Color change kinetics of okra undergoing microwave drying," Drying Technology, vol. 25, no. 5, pp. 925-936, 2007.

[35] A. Sarimeseli, "Microwave drying characteristics of coriander (Coriandrum sativum L.) leaves," Energy Conversion and Management, vol. 52, no. 2, pp. 1449-1453, 2011.

[36] A. Balbay and Ö. Şahin, "Microwave Drying Kinetics of a ThinLayer Liquorice Root," Drying Technology, vol. 30, no. 8, pp. 859-864, 2012.

[37] I. Doymaz, "Thin-layer drying characteristics of sweet potato slices and mathematical modelling," Heat and Mass Transfer, vol. 47, no. 3, pp. 277-285, 2011.

[38] E. Demirhan and B. Özbek, "Color change kinetics of microwave-dried basil," Drying Technology, vol. 27, no. 1, pp. 156-166, 2009.

[39] G. Dadalı, E. Demirhan, and B. Özbek, "Color change kinetics of spinach undergoing microwave drying," Drying Technology, vol. 25, no. 10, pp. 1713-1723, 2007.

[40] E. Demirhan and B. Ozbek, "Color change kinetics of tea leaves during microwave drying," International Journal of Food Engineering, vol. 11, no. 2, 2015.

[41] H.-W. Xiao, C.-L. Law, D.-W. Sun, and Z.-J. Gao, "Color Change Kinetics of American Ginseng (Panax quinquefolium) Slices During Air Impingement Drying," Drying Technology, vol. 32, no. 4, pp. 418-427, 2014.

[42] M. Shahabi, S. Rafiee, S. S. Mohtasebi, and S. Hosseinpour, "Image analysis and green tea color change kinetics during thinlayer drying," Food Science and Technology International, vol. 20, no. 6, pp. 465-476, 2014. 


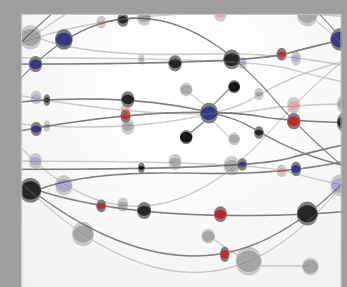

The Scientific World Journal
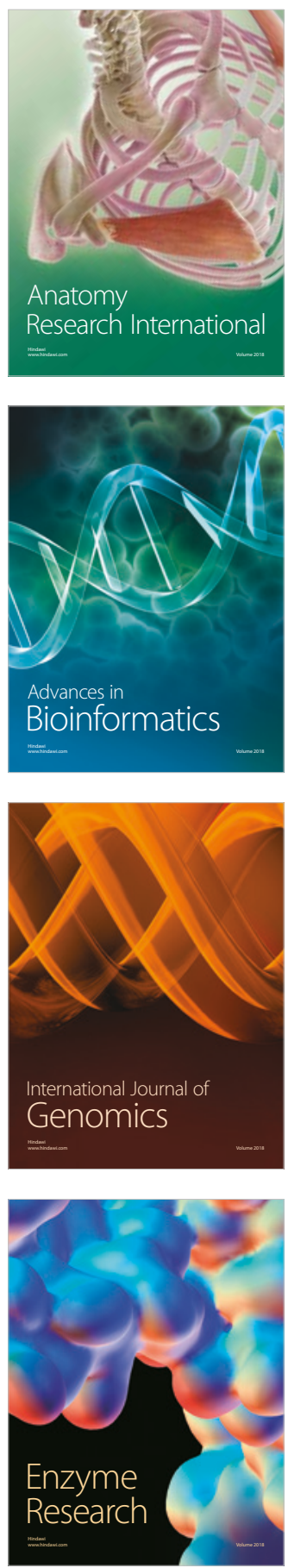
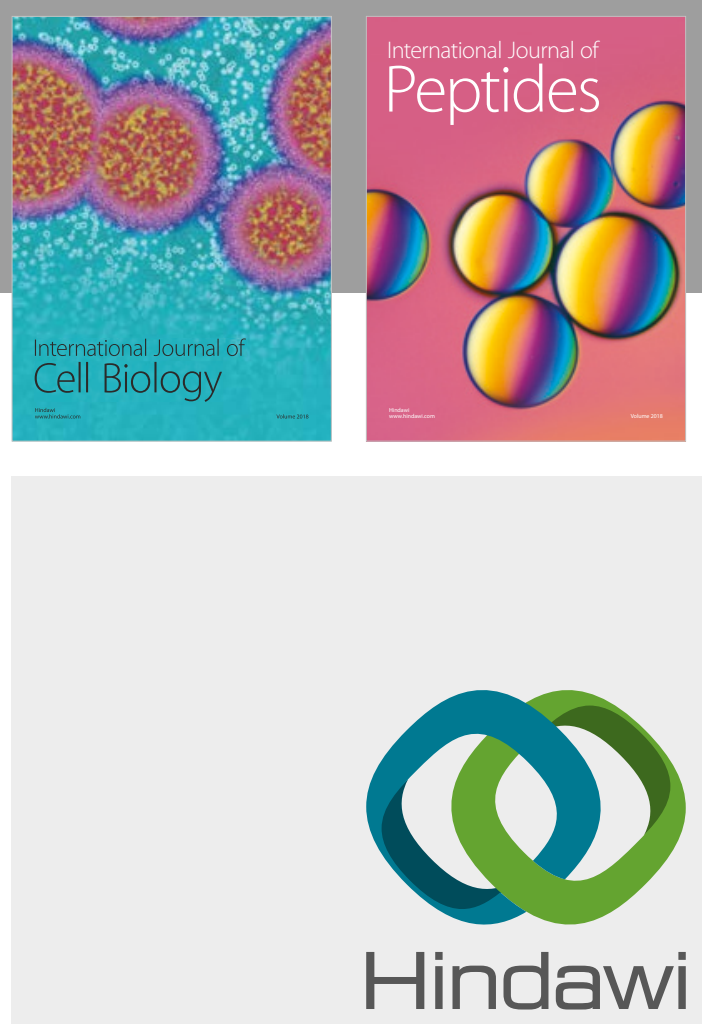

Submit your manuscripts at

www.hindawi.com
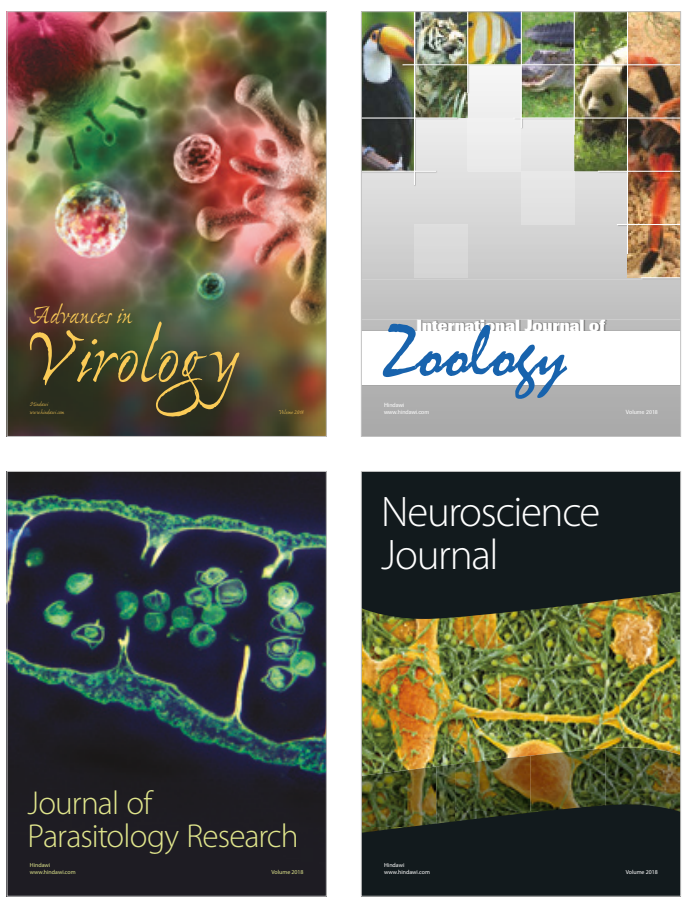
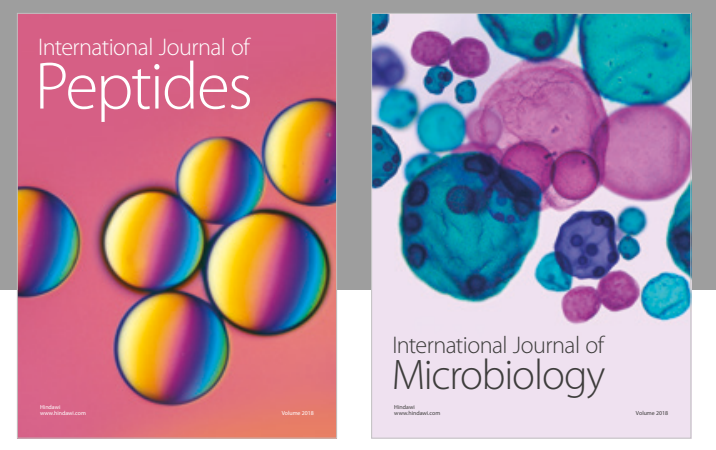

nternational Journal of Microbiology
Journal of
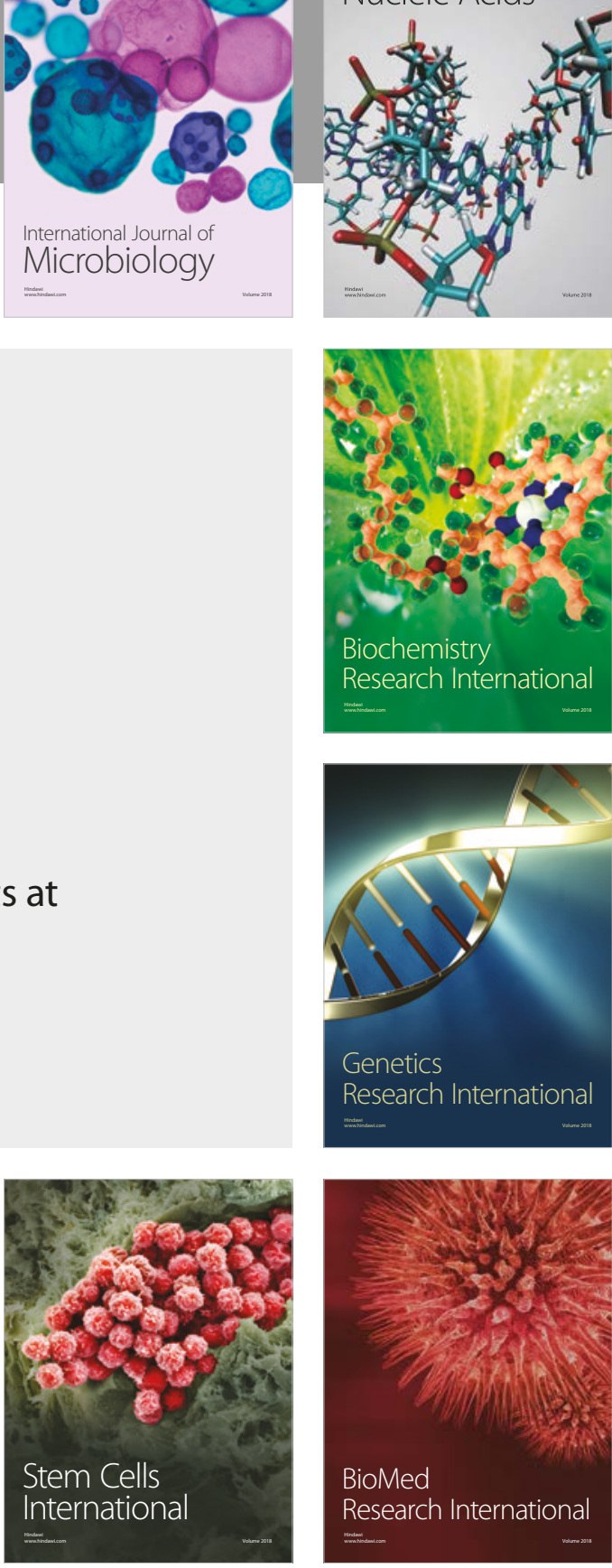
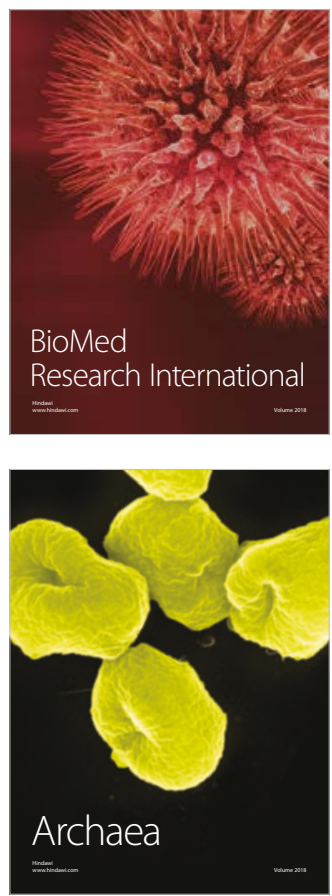